\title{
Reflexões sobre os conceitos de cidadania e sujeito em psicanálise na Atenção Psicossocial
}

\section{Reflections on the concepts of citizenship and subject in psychoanalysis in Mental Health}

\section{Reflexiones sobre los conceptos de ciudadanía y sujeto en psicoanálisis en la Salud Mental}

\author{
Joyce Hilario Maranhão* \\ Universidade Estadual do Ceará - UECE, Fortaleza, Ceará, Brasil
}

Camilla Lopes Araújo Vieira**

Universidade Federal do Ceará - UFC, Sobral, Ceará, Brasil

\begin{abstract}
RESUMO
A captura da cidadania como princípio das práticas de saúde mental e discurso a ser incorporado subjetivamente pelo louco cria um impasse na própria atitude subversiva pretendida pela Reforma Psiquiátrica Brasileira. A Psicanálise sustenta o ato de escuta do sujeito, em uma posição de autoria, responsabilização pelo seu sofrimento e sustentação de seu desejo, estando aí uma possível contribuição da psicanálise para a luta antimanicomial. A partir de uma pesquisa analítica, de enfoque qualitativo, aborda-se os significantes de cidadania e de sujeito em psicanálise e quais as implicações práticas e políticas de tais concepções para o cotidiano dos Centros de Atenção Psicossocial. Aposta-se em uma contribuição teórica e política ao apontar as diferenças entre o trabalho orientado pela cidadania e aquele orientado pelos efeitos do inconsciente, sem objetivar, contudo, uma oposição entre essas perspectivas de trabalho.
\end{abstract}

Palavras-chave: Saúde mental, Psicanálise, Cidadania.

\begin{abstract}
The capture of citizenship as a principle of mental health practices and discourse to be subjectively incorporated by the crazy creates a standoff in the subversive attitude intended by the Brazilian Psychiatric Reform. Psychoanalysis supports the act of listening to the subject, in a position of authorship, responsibility for their suffering and support of their desire, being there a possible contribution of psychoanalysis to the antimanicomial fight. Based on an analytical research, with a qualitative focus, the article approaches the signifiers of citizenship and subject in psychoanalysis and what are the practical and political implications of such conceptions for the daily life of the Psychosocial Care Centers. It is based on a theoretical and political contribution in pointing out the differences between work oriented by citizenship and that guided by the effects of the unconscious, however, without objecting to an opposition between these perspectives of work.
\end{abstract}

Keywods: Mental health, Pychoanalysis, Citizenship. 


\begin{abstract}
RESUMEN
La captura de la ciudadanía como principio de las prácticas de salud mental y discurso a ser incorporado subjetivamente por el loco crea una dificultad en la actitud subversiva pretendida por la Reforma Psiquiátrica Brasileña. El psicoanálisis sostiene el acto de escucha del sujeto, en una posición de autoría, responsabilización por su sufrimiento y sustentación de su deseo, estando ahí una posible contribución del psicoanálisis a la lucha antimanicomial. A partir de una investigación analítica, de enfoque cualitativo, se abordan los significantes de ciudadanía y de sujeto en psicoanálisis y cuáles las implicaciones prácticas y políticas de tales concepciones para el cotidiano de los Centros de Atención Psicosocial. Se apunta en una contribución teórica y política al apuntar las diferencias entre el trabajo orientado por la ciudadanía y aquel orientado por los efectos del inconsciente, sin embargo, sin objetivar una oposición entre esas perspectivas de trabajo.
\end{abstract}

Palabras clave: Salud Mental, Psicoanálisis, Ciudadanía.

A Reforma Psiquiátrica Brasileira-RPB iniciou um debate técnico e político sobre o campo da saúde mental e formulou uma intensa crítica ao modelo de assistência psiquiátrica existente no país na década de 1980, voltando-se para as questões relacionadas à perda de identidade e da dignidade humana e indo de encontro a práticas de violência perpetradas nas instituições manicomiais. A denúncia contra esse modelo de tratamento em saúde mental é impulsionada dentro de um contexto nacional de transformação política, jurídica e econômica que favorece a luta pelos direitos sociais, em que a cidadania se torna o princípio orientador e um significante que marca os movimentos sociais em prol da garantia de políticas públicas nas áreas da saúde, educação, assistência social, dentre outras reivindicações sociais (Amarante, 1995, 2003, 2007; Barros, 1994; Birman, 1992; Carvalho, 2009; Lancetti \& Amarante, 2014; Resende, 1994).

A busca pela cidadania enquanto princípio das reformas psiquiátricas na Itália e no Brasil no século XX ocorre por meio do enfrentamento a instituições asilares, desinstitucionalização de práticas forjadas para lidar com a loucura, extrapolando somente à desospitalização, e da inclusão social do louco em serviços substitutivos de base comunitária, exigindo novas perspectivas teóricas e práticas para o cuidado de pessoas com algum sofrimento psíquico. A questão dos direitos humanos assume uma expressão singular, pois trata da luta pela inclusão do louco como sujeito de direitos e da produção de novos direitos para esse indivíduo, extrapolando o setor saúde e se ampliando para outras políticas sociais, a exemplo da educação, trabalho, esporte, lazer, cultura (Amarante, 1995, 2003, 2007; Barros, 1994; Lancetti \& Amarante, 2014). 
A cidadania enquanto resposta do Estado para diminuir as desigualdades socioeconômicas produzidas pelo sistema capitalista (Behring \& Bochetti, 2011; Fleury \& Ouverney, 2012; Marshal, 1967; Montaño, 2007) cumpre-se nas estratégias estatais de proteção social dos cidadãos por meio de políticas públicas que intentam integrar socialmente a todos. Deste modo, a política pública de saúde irá tentar incluir o louco enquanto um indivíduo em sofrimento, mas que tem seus direitos e deveres de cidadão garantidos pelo Estado. Esse sujeito do coletivo, que encontra no lugar do universal uma possibilidade de compartilhamento de valores culturais e morais, se distingue do sujeito singular que tem em sua particularidade uma ética do desejo pertinente ao modo como constitui e se fez constituir em sua história familiar.

Em Psicanálise, a noção de sujeito corresponde há um posicionamento na linguagem, por meio da inserção neste campo e como efeito deste, possibilitando a representação dos objetos no mundo e a significação das experiências (Elia, 2000, 2010; Freud, 1914/2010a, 1915/2016; Lacan, 1953-1954/1996, 1949/1998). A referência ao sujeito de desejo não define uma categoria em si, pois não há valores que possam o definir, uma vez que o sujeito ocupa o lugar de agente que produz a verdade sobre si para um outro capaz de sustentar uma posição de escuta (Elia, 2010; Furtado, Araújo, \& Santos, 2014).

O intuito deste estudo é compreender como a literatura aborda os significantes de cidadania e de sujeito em psicanálise e quais as implicações práticas e políticas de tais concepções para o cotidiano dos Centros de Atenção Psicossocial. Consideramos que este trabalho pode contribuir de modo teórico e político para o campo da saúde mental e da Reforma Psiquiátrica no Brasil ao apontar as diferenças entre o trabalho orientado pela cidadania e o trabalho orientado pelos efeitos do inconsciente, sem objetivar, contudo, uma oposição entre essas perspectivas de trabalho.

\section{Metodologia}

Apresentamos uma pesquisa bibliográfica de enfoque qualitativo, realizada entre os anos de 2016 a 2017, em que se tratou de percorrer a história dos conceitos de sujeito em psicanálise e cidadania na Reforma Psiquiátrica Brasileira. Para tanto, optou-se por uma análise das obras bibliográficas clássicas do campo da saúde mental que versam sobre a história da reforma psiquiátrica no Brasil e a construção da política nacional de atenção psicossocial articulada à ideia de cidadania e/ou ao trabalho de psicanalista na saúde mental que abordam o tema do sujeito em psicanálise. A Psicanálise nos dá suporte na estreita relação que estabelece entre pesquisa e clínica. 
Assim, nossa abordagem possibilitou uma leitura analítica dos caminhos de autores no campo da atenção psicossocial e da reforma psiquiátrica no contexto brasileiro.

\section{Resultados e Discussão}

\section{O Louco Cidadão: Processos de Institucionalização da Loucura e da Cidadania na Saúde Mental}

Para dialogarmos sobre a categoria cidadania em articulação com o campo da saúde mental resgatamos como este conceito historicamente foi associado à loucura. A inserção do louco no discurso da cidadania ocorreu com o advento da Revolução Francesa (Amarante, 1995, 2003; Birman, 1992; Lancetti \& Amarante, 2014; Resende, 1994), "quando as individualidades passaram a ser representadas como sendo iguais perante a lei, não obstante a evidente existência de suas diferenças" (Birman, 1992, p. 74). Essa captura da loucura pelas ideias de igualdade e de cidadania somente foi possível devido ao advento das ideias iluministas e à ascensão do Estado burguês na transição da Idade Moderna para a Contemporânea.

A necessidade da eliminação da hierarquia jurídica se fez necessária a fim de permitir o acesso aos direitos civis ao final do século XVIII e aos direitos políticos no século XIX (Behring \& Bochetti, 2011; Marshal, 1967). Assim, a ideia de cidadania não condiz com a ausência das diferenças sociais entre os sujeitos, uma vez que a universalização dos direitos de liberdade, igualdade e fraternidade é ofertada de modo parcial, sendo a cidadania restrita ao direito à proteção e ao cuidado médico pelo Estado.

A inauguração do Estado burguês pressupõe um modo de produção e reprodução das relações sociais em que todos devem contribuir e usufruir dos bens sociais produzidos pela coletividade, ao mesmo tempo em que divide os homens entre a classe capitalista, aquela que detém os meios de produção (terra, matérias-primas, máquinas e instrumentos de trabalho), e a classe proletária, aquela que tem a força de trabalho (Fleury \& Ouverney; 2012; Montaño, 2007).

Os grupos considerados inaptos para a livre venda da força de trabalho e para contribuir com o desenvolvimento da nação vão sofrer processos de vigilância, reclusão e tratamento moral e/ou punitivo. O louco será capturado por esse discurso por meio da medicina, que servirá para a adaptação e manutenção do homem para o trabalho (Amarante, 1995; Birman, 1992; Foucault, 1979, 2005; Lancetti \& Amarante, 2014; Resende, 1994), na qual a cidadania é, ao mesmo tempo, a causa da desvalorização e estigmatização do louco e o caminho do seu tratamento. A 
problemática é discutir como a cidadania aparece como demanda para a pessoa com sofrimento e como o Estado e seus representantes podem sustentar outro lugar para esse sujeito que não seja somente o de cidadão.

Para Birman (1992), o direito a ter assistência psiquiatria em uma instituição asilar é um paradoxo, uma vez que, na leitura racionalista da sociedade contemporânea, o louco é um indivíduo que não possui razão e nem vontade própria. Portanto, não é um ser apto para a produção e a vida social, ao mesmo tempo em que se reconhece a necessidade da intervenção estatal para recuperar sua sanidade e torná-lo um cidadão. Decorre-se dessa situação a existência de uma cidadania restrita com a promessa de uma futura cidadania plena, onde o louco estará em convívio comunitário com os demais cidadãos.

Consideramos que a ampliação e disponibilidade de direitos sociais no século XX não garantem que haja de fato o exercício da cidadania, principalmente em sociedades em que o acesso a tais direitos está atrelado a condicionalidades socioeconômicas, onde 0 indivíduo recebe algum benefício pela constatação de sua incapacidade para prover o seu próprio bem-estar. Contudo, não fazemos uma crítica à proteção social e à disponibilidade das políticas públicas, uma vez que sabemos que elas existem enquanto apaziguadoras das desigualdades sociais produzidas pelas relações entre Estado, sociedade e mercado, mas faz-se aqui a ressalva de que as próprias políticas públicas são engendradas dentro de um modo de produção capitalista que transforma o desejo em objeto de consumo e que interfere diretamente nas formas de regulação da ordem social pelo Estado (Fleury, 2012; Montaño, 2007).

Ao compreendermos o modo como foram engendradas as relações sociais ao longo dos séculos XIX e XX, conseguimos ampliar o olhar para os modelos de assistência psiquiátrica e de cuidado em saúde mental destinado à loucura. O modelo alienista de cuidado em saúde mental surge em uma conjuntura política e econômica em que razão e aptidão para o trabalho caminhavam paralelamente. Estar apto para participar da produção coletiva de bens materiais passou a seu uma exigência a todos os cidadãos, estando os direitos sociais atrelados à capacidade de cumprir com o dever de contribuir para a sociedade. Deste modo, compreendemos que o louco é incluído pelo viés da cidadania para servir ao Estado e ao mercado do mesmo modo que os demais ditos cidadãos, igualando e universalizando a norma social a que a loucura escapa (Resende, 1994).

A desigualdade social, a violência e a exclusão econômica produzidas pelo sistema de produção capitalista atingiram amplamente aqueles que estavam em posições hierárquicas inferiores. Essa conjuntura macrossocial é a responsável tanto pelo adoecimento mental como pelos modos de punição e cerceamento da liberdade contra aqueles 
que subvertem a norma social. Portanto, a cura da loucura somente é possível com o combate das circunstâncias que a produz (Amarante, 1995; Basaglia, 1979, 1985; Resende, 1994).

Para Basaglia (1979, 1985), o contexto das instituições manicomiais propicia à reprodução da violência e exclusão fundamentadas na suposta culpa do louco pelo seu adoecimento. Assim, não resta outra estratégia que não a extinção total dessas "instituições da violência" (Basaglia, 1979, p. 102) e a criação de outro modelo de cuidado da loucura que tenha o território como espaço privilegiado de suas práticas e a garantia de condições mínimas de alimentação, habitação e de trabalho para se viver dignamente e ter uma consciência de vida.

A cidadania e os direitos sociais no Brasil estiveram, por muito tempo, restritos à inserção do indivíduo na economia formal. Assim, a assistência à saúde para a maioria dos brasileiros era praticada pelas filantropias e ações estatais pontuais. Após a era Vargas, tem-se a oferta de assistência em serviços público-privados para aqueles que possuíam carteira de trabalho e vínculo empregatício, ainda variando de acordo com o poder de barganha e pressão de cada categoria profissional (Resende, 1994; Desviat, 2015). O louco é mais um précidadão que não tem garantido os seus direitos e possui uma cidadania restrita (Lancetti \& Amarante, 2014).

O processo de institucionalização de práticas de cuidado à loucura nas instituições psiquiátricas asilares no Brasil reproduz ideias e práticas de violência e cerceamento da liberdade dos loucos, próximas àquelas praticadas em instituições manicomiais europeias (Resende, 1994; Dunker \& Neto, 2015). Até os anos 50 do século XX há uma perpetuação de um modo de tratamento do louco restrito ao fator orgânico, sem considerar os aspectos culturais, sociais e singulares de cada pessoa, contribuindo para a objetificação e repressão do indivíduo, com uma baixa qualidade das condições sanitárias e da assistência médica nos hospícios de todo o país. Nas décadas de 60 e 70, durante o governo militar, a intensa contratação de hospitais privados para assistir os trabalhadores e seus dependentes contribuintes do Instituto Nacional da Previdência Social- INPS não foi capaz de transformar a realidade do tratamento da loucura; ao contrário, ampliou a superlotação dos manicômios privados, o tempo de internação de cada paciente e a cronificação das pessoas.

A reeducação pelo trabalho e para o trabalho também foi um tratamento implantado em solo brasileiro, mas não alcançou sucesso devido às características culturais e econômicas do país (Resende, 1994). O movimento reformador da saúde mental brasileira se aproxima dos ideais da psiquiatria democrática italiana e das ideias basaglianas, em que se faz uma crítica ao tratamento laboral inaugurado por Pinel (Resende, 1994; Basaglia, 1979, 1985; Elia, 
2015), reposicionando o trabalho em uma perspectiva de produção cooperativa, impulsionando os processos de cidadania, subjetivação e sociabilidade (Lancetti \& Amarante, 2014).

Nos primeiros anos da década de 70 , as críticas à "indústria da loucura" (Resende, 1994, p.62) e a presença de militantes e pesquisadores da saúde mental na gestão de serviços governamentais dos estados e do país, somadas aos fatores econômicos da conjuntura brasileira, modificaram a assistência psiquiátrica brasileira, onde se buscou a redução da quantidade de pessoas internadas e do tempo de internação.

A assistência psiquiátrica é apenas um dos temas que compõem a agenda de discussão da Reforma Psiquiátrica Brasileira-RPB (Amarante, 2003, 2007), cujo objetivo principal é a desinstitucionalização das práticas de cuidado à loucura, para além da desospitalização, e o deslocamento do louco do lugar de nãocidadão para o de cidadão (Barros, 1994; Birman, 1992). A RPB defende a cidadania como princípio orientador do cuidado das pessoas com sofrimento e como base para o tratamento em espaços comunitários, preferencialmente no território de origem desses indivíduos, a fim de que as mesmas possam habitar a cidade e exercer sua condição de cidadão (Amarante, 2003; Birman, 1992; Lancetti \& Amarante, 2014).

A defesa e a busca de direitos considerados essenciais para a garantia da cidadania do louco é vista como o pagamento de uma dívida do Estado e da sociedade por ter permitido a exclusão social dos doentes mentais durante um longo tempo, em que o tratamento nas instituições manicomiais existiu como única forma de assistência às pessoas com doença mental (Birman, 1992). No entanto, compreendemos que não há a superação da dualidade entre inclusãoexclusão social, já que a defesa da existência de espaços de cuidado em saúde mental se dá por aspectos sociais e econômicos, onde 0 louco ocupa o lugar de cidadão.

De acordo com Barros (1994), o próprio conceito de saúde mental passa a ser questionado pela RPB, pois a terminologia está mais próxima do campo científico do que da experiência humana da loucura. Ressalta-se que esta crítica é observada na dimensão jurídico-política, na qual a rede de cuidado passa a ser nomeada de Atenção Psicossocial, a fim de demarcar um campo mais amplo de intervenção e denunciar o viés institucionalizador do antigo modelo de assistência psiquiátrica, além de tornar o louco um cidadão.

Com base em uma dimensão teórico-metodológica, em que se compreende que há uma ideologia e práticas excludentes por trás das terminologias que coabitam o universo da saúde mental, há uma desconstrução do conceito de clínica, compreendida por Amarante (2003, 2007) como sinônimo de isolamento terapêutico ou tratamento moral na perspectiva de cuidado existente no século XIX. 
Para o autor, a clínica da RPB é uma proposta de desinstitucionalização, com base em um processo ético-estético, em que há a produção de possibilidades e de sociabilidades e uma nova subjetividade: o sujeito de direito, que por sua vez tem novos direitos. Esta inserção social do louco se relaciona à dimensão sociocultural e ao maior objetivo da Reforma Psiquiátrica Brasileira, pois se aposta que a garantia de direitos sociais permite a transformação do lugar social da loucura ao ser igualado ao estatuto de cidadão como as demais pessoas (Amarante, 2003, 2007).

Em nossa leitura compreendemos que o objeto da clínica da atenção psicossocial é o louco enquanto cidadão. Isto reverbera diretamente na dimensão técnico-assistencial, cujo novo modo de fazer/produzir o cuidado busca a superação da ideia de loucura como perda da razão e de práticas de tutela e vigilância exercidas na relação institucional entre técnico e paciente na clínica da medicina naturalista. A ideia de colocar a doença entre parênteses de Basaglia é reinterpretada por Amarante (2007) como uma clínica que também é posta entre parênteses e que terá como foco o sujeito da experiência.

Acreditamos que apontar a cidadania como princípio ético orientador das práticas de atenção psicossocial cria um impasse na própria atitude subversiva pretendida pela RPB, uma vez que o que se aponta é uma clínica que já traz um saber sobre esse sujeito, a saber: a cidadania como discurso a ser incorporado subjetivamente pelo indivíduo (Amarante, 2003, 2007).

Resguardando todas as diferenças entre o modelo manicomial e o modelo instituído pela reforma psiquiátrica brasileira, percebe-se que as práticas de assistência à loucura tentam marcar o corpo do louco pelo significante da cidadania. No primeiro modelo há a exclusão de seus direitos em prol de uma recuperação da razão que lhe garantiria a cidadania plena (Birman, 1992; Lancetti \& Amarante, 2014; Resende, 1994). No segundo há a libertação do louco para o tratamento e convívio comunitário que, com base na ocupação de espaços sociais, permitiria o exercício da cidadania (Amarante, 1995; Lancetti \& Amarante, 2014; Resende, 1994).

Alinhamos nossas reflexões à ideia defendida por Birman (1992) de que há um paradoxo entre a loucura e a cidadania na forma em que são pensadas pelas reformas psiquiátricas italiana e brasileira, pois a loucura continua identificada a uma forma de alienação social e a solução para a inclusão do louco seria a instauração da cidadania, da consciência de vida e o reconhecimento positivo de si (Birman, 1992). Para o autor, a contradição está na relação dual entre um estatuto negativo e outro positivo da cidadania, pois o resgate da cidadania do louco pelos movimentos reformistas e sociais do campo da saúde mental ocorre com base na tentativa de torná-lo cidadão a partir de uma assistência psiquiátrica e proteção do Estado. 
Ser encoberto pelo manto da cidadania não garante por si só que este signo fará parte da rede de significantes do louco, isto, é, terá algum sentido para a pessoa que sofre. As práticas instituídas pela RPB nos serviços assistenciais de atenção psicossocial são orientadas por esse princípio partindo de uma cidadania enquanto direito político para todos e que, por sua vez, garante o acesso a direitos sociais, a exemplo da saúde, mas que não dialogam com a demanda de cada sujeito para quem este discurso é direcionado.

Compreendemos que este lugar do cidadão não tem conseguido comportar a complexidade e a verdade que o louco aponta para os trabalhadores da saúde mental. Concordamos que não há o reconhecimento de que existe verdade na experiência da loucura e de que esta tem a marca fundante de um sujeito, o que há é uma "negativização da experiência da loucura" (Birman, 1992, p.87) e a oposição entre as categorias de verdade e de subjetividade mantendo as mesmas contradições do discurso alienista.

O discurso freudiano já reconhecia a especificidade da experiência da loucura e a presença da verdade fundada no sujeito (Birman, 1992). Desde os primórdios da Psicanálise há a preocupação de seu fundador com as questões sociais que afetam a subjetividade humana e a articulação com a saúde pública, ou seja, há uma preocupação com a oferta de assistência gratuita pautada na ética do sujeito do desejo para aqueles que sofrem psiquicamente, não necessariamente vinculada a questões socioeconômicas, mas à demanda elaborada por aquele que sofre (Freud, 1919/2010b; Figueiredo, 2009).

A clínica psicanalítica nos ensina que devemos sustentar a escuta do sujeito do desejo, responsabilizando-o pelo seu sofrimento e pelos modos como faz laço social. Por conseguinte, pode dessa escuta surgir algo que o recoloque em uma posição de autoria e sustentação de seu desejo, estando aí uma possível contribuição da psicanálise para a Reforma Psiquiátrica Brasileira. Apontamos que a Psicanálise não é a solução para toda a miséria humana, mas não podemos deixar de apontar que se, historicamente, o campo psicanalítico foi e ainda é fértil aos campos da Saúde Coletiva, da Saúde Mental e da Saúde Pública, hoje existe um trabalho de depreciação da teoria psicanalítica por aqueles que advogam, ideologicamente, contra a clínica.

Acreditamos que para que a reforma psiquiátrica brasileira seja efetivada é necessário considerar o coletivo - para todos, na garantia do um a um - no que demarcamos como singular. Nesse sentido, trazemos no próximo capitulo o que entendemos serem as contribuições da Psicanálise para o campo da saúde mental e da reforma psiquiátrica brasileira. 


\section{Sujeito do desejo e o campo da Saúde Mental}

A Psicanálise se insere no Brasil na década de 20 por meio da implantação de instituições psicanalíticas e do ensino de suas diferentes vertentes, em um primeiro momento, entre intelectuais e artistas vanguardistas com um caráter crítico e subversivo e, posteriormente, entre médicos e pedagogos ligados ao movimento higienista. Assim, a psicanálise foi ensinada para fins de profissionalização, especificamente na região sudeste do país (Dunker \& Neto, 2015).

De acordo com Dunker e Neto (2015), a entrada das ideias psicanalíticas em solo brasileiro contribuíram para a constituição do campo da saúde mental, por meio de um processo de institucionalização do sofrimento e de uma regulação das formas de vida destoantes da norma social pelo Estado, e para a consequente produção e expansão do complexo asilar.

Cabe-nos apreciar o ponto de virada de posição de alguns psicanalistas diante do contexto histórico e social brasileiro no decorrer do século $\mathrm{XX}$, a saber: ditadura militar e cerceamento da liberdade de expressão, acirramento das desigualdades sociais, desinvestimento financeiro e sucateamento das instituições públicas, exclusão social principalmente de grupos minoritários, a exemplo do louco, ao mesmo tempo em que movimentos sociais, profissionais e políticos lutavam contra o regime e em prol da garantia de direitos básicos para a manutenção da vida e da participação política.

$\mathrm{Na}$ década de 80, alguns psicanalistas no Brasil assumem uma posição de diálogo com os movimentos político-sociais contribuindo para a consolidação da política pública de saúde e para a criação de equipamentos de saúde que consideram, além da cidadania, a ética e a escuta do sujeito dentro de instituições públicas, propondo-se a realizar a promoção da saúde mental (Alberti, 2000; Elia, 2010; Rinaldi, 2002, 2005, 2006; Tenório, 2002).

Neste momento, percebemos que não se trata de ensinar a psicanálise como mais uma técnica para tratar a loucura, mas de transmitir e sustentar um conhecimento que advém do próprio sujeito na clínica psicanalítica, considerado o único capaz de falar de si com seus recursos possíveis. Não se trata de um saber esotérico ou de um discurso produzido pela psiquiatria que deve ser assimilado pelo louco como no século XVIII (Dunker \& Neto, 2015), mas de um saber inconsciente que se produz discursivamente pela articulação dos campos do sujeito e do Outro (Elia, 2010; Rinaldi, 2002).

A categorização da noção de sujeito (do inconsciente) surge com os textos de Jacques Lacan. No entanto, embora seja preciso didaticamente defini-lo para fins de reconhecimento de sua existência, sabe-se que o sujeito não é um conceito em si, uma vez que esta é uma categoria que se confere a uma experiência psíquica. 
Para a psicanálise, o humano é um ser de linguagem. Assim são as palavras que denunciam a existência de um sujeito a partir dos tropeços do inconsciente quando este se põe a falar de sua experiência (Elia, 2010; Rinaldi, 2002; Lacan, 1972-1973/1985, 1963-1964/1988).

Lacan elaborou a teoria dos quatro discursos que regulam o laço social do sujeito com a realidade, apresentando quatro posições na linguagem: do mestre, da histérica, do analista e do universitário, que indicam a posição do sujeito do desejo e seu ponto de gozo (Alberti, 2000; Coutinho Jorge, 2002; Elia, 2010; Rinaldi, 2002; Lacan, 1972-1973/1985; Darriba, 2015). Esses discursos explicitam as formas de lidar com a falta inscrita no processo de constituição psíquica, circunscrevendo e contornando o que escapa da simbolização do real. Os matemas $\mathrm{S} 1, \mathrm{~S} 2, \$$ e objeto a giram em lugares fixos, assumindo a posição de agente, outro, produto e verdade, posteriormente esses lugares foram nomeados de semblante, gozo, mais-de-gozar e verdade, respectivamente.

Este trabalho irá delimitar apenas os discursos do mestre e do analista, apontados por Lacan como avessos (Alberti, 2002). Esta escolha se dá em relação ao uso das categorias de cidadania e sujeito no campo da saúde mental, uma vez que identificamos que estes termos são recorrentes na literatura, sendo abordados como orientadores das práticas dos profissionais que atendem pessoas em sofrimento. Lembramos que este sujeito acima citado não necessariamente é o sujeito tal como concebido no campo psicanalítico.

Cada discurso existe em referência ao Outro, impulsionado e sustentado por uma verdade, o agente ordena um discurso que é dirigido a outro a fim de obter deste uma produção discursiva (Elia, 2000; Lacan, 1972-1973/1985). De acordo com Coutinho Jorge (2002), o lugar do agente é a dominante de cada discurso. Assim, a depender do lugar em que o sujeito é colocado, pode vir a assumir a posição de produtor da verdade sobre si quando ocupa o lugar do outro a quem esse discurso se direciona (discurso do analista) ou a posição de sustentação de um discurso que não é seu, mas ao qual está subjugado tal como um escravo (discurso do mestre).

No processo de constituição psíquica é necessário que o discurso do mestre opere a fim de que o bebê possa se alienar no desejo de sua mãe. Assim, o adulto $(\$)$ sustenta um significante-mestre $\left(S_{1}\right)$ que ordena um discurso ao qual o bebê irá se identificar $\left(S_{2}\right)$ e que terá como produto a sua castração (objeto a). Na estrutura do discurso do mestre, $\mathrm{S}_{1}$ é a função de significante sobre a qual se apoia a essência do senhor (aquele que sustenta e ordena uma verdade) e o S2 é o campo próprio do escravo (aquele a quem se direciona a verdade e que terá que lidar com os impasses de sustentar um desejo do Outro) (Alberti, 2000; Elia, 2010; Lacan, 1972-1973/1985). 
Em determinado momento, o bebê subverte o discurso do senhor com seu próprio desejo. É a função paterna que aponta a falta narcísica para o mestre, cessando o gozo do dominador, e instaura a falta para o sujeito que emerge no campo do desejo (Lacan, 19721973/1985). O louco também subverte o discurso agenciado pelos profissionais de saúde mental, produzindo seu próprio discurso sobre a loucura e o seu modo de constituir os laços sociais, demonstrando as fissuras de se trabalhar com um valor que não pertence ao inconsciente.

A Portaria no 3.088/2011 que institui a Rede de Atenção Psicossocial traz a cidadania como princípio orientador de seus serviços. Deste modo, todos que participam da oferta dos serviços dessa política social devem garantir que o louco seja inserido socialmente como um cidadão. Por vezes, percebemos que a cidadania se apresenta como um saber já dado e incorporado no olhar e na palavra de seus agentes que se direcionam a um sujeito da razão, que deve se identificar e sustentar as práticas de reabilitação ofertadas pelos serviços da atenção psicossocial.

Para Dunker e Neto (2015) e Rinaldi (2002), nos Centros de Atenção Psicossocial-CAPS os trabalhadores de saúde mental ocupam a posição de comando $\left(S_{1}\right)$, agenciando o discurso da cidadania sobre o outro $\left(\mathrm{S}_{2}\right)$, o alienado, com o objetivo de promover uma mudança na cadeia de suas ideias. O produto do discurso do mestre é a constituição de um objeto $a$, isto é, o transtorno mental, saber disjunto do sujeito e que por isso retira sua autonomia.

Os profissionais que atuam com a loucura são apontados como agentes da cidadania, sejam os trabalhadores de nível superior ou os profissionais de nível técnico, médio e fundamental que atuam na recepção, segurança, serviços auxiliares de limpeza e alimentação e trabalhos técnicos, incluindo os facilitadores de terapias artísticas e de práticas alternativas de saúde. Mesmo que não se reconheçam enquanto operadores de uma política social focada na oferta de um serviço a partir de condicionalidades atribuídas ao cidadão, os trabalhadores em suas práticas podem reproduzir o discurso do mestre, ou seja, do especialista que determina a demanda do outro.

Afirmar que aos trabalhadores de saúde cabe agenciar a cidadania não significa desconsiderá-los em outras possibilidades de discurso, uma vez que se sabe que o discurso do mestre é recalcador para o próprio mestre. Ele não reconhece a verdade que sustenta, embora não sem sofrimento, uma vez que as constantes queixas sobre aguentar a miséria da loucura e os impasses de lidar com a demanda do sujeito e a demanda do Estado não exclui o mestre do discurso que o condiciona, antes o reforça através de uma ideia ilusória de que dele não faz parte (Lacan, 1972-1973/1985).

O discurso do mestre é o avesso do discurso do analista, pois o analista sustenta a posição de causa de desejo (objeto a), faz 
semblante para o desejo do outro (\$), a partir da suposição de saber no sujeito, que terá como produto de seu trabalho seus próprios significantes $\left(\mathrm{S}_{1}\right)$ (Alberti, 2000; Elia, 2000; Lacan, 19721973/1985). Na relação transferencial com o analista ou por quem possa sustentar esse lugar de escuta e não-saber que causa no outro uma produção discursiva nos centros de atenção psicossocial, é o lugar no qual o louco poderá elaborar os significantes de sua história e de seu sofrimento, possibilitando a retificação subjetiva que o implica com seu sintoma e seu tratamento nos serviços da rede de atenção psicossocial.

Receber os dejetos que ninguém mais quer saber é o lugar de santo do analista (Lacan, 2003; Mira, 2005), isto é, escutar o saber inconsciente do sujeito sobre si, sua loucura e o caminho para o seu tratamento é sustentar um lugar de esvaziamento do saber prévio. Assim, não se trata de dar voz ao louco para que este seja incluindo enquanto cidadão em um leque de serviços institucionais (Ferreira, 2013), mas oferecer a escuta para que em sua diferença o louco possa se implicar com seus sintomas e tratamento, escolhendo a quais serviços ele desejará se vincular.

Compreendemos que as produções dos discursos são modos de estruturação dos laços sociais entre os seres falantes e que os serviços públicos de saúde mental comportam diferentes discursos e práticas que pensam, tratam e fazem caber a loucura nos serviços assistenciais da reforma psiquiátrica (Ferreira, 2013; Lo Bianco, 2015). Percebemos, pela experiência em alguns Centros de Atenção Psicossocial e Centros de Saúde da Família que executam ações e serviços de saúde mental, que essa pluralidade pode estagnar 0 trabalho nos serviços de saúde mental e a própria luta antimanicomial quando as línguas são diferentes ou não encontram nenhuma tradução possível que sirva de interlocução entre os profissionais, retornando a práticas manicomiais em serviços que a priori teriam a função de criar práticas de cuidado à loucura que superem a lógica centrada na terapêutica medicamentosa, que considera o sofrimento primordialmente como efeito de fatores neuroquímicos, e de adequação do indivíduo.

No campo das políticas públicas de saúde mental preconizadas pelo movimento de reforma psiquiátrica, seja na assistência, na militância ou na formação universitária e profissional, é necessária a retomada da dimensão clínica. Mais uma vez, reiteramos que não significa afirmar que o social, o coletivo e a cidadania sejam abolidos. Antes é imprescindível retomar o caráter questionador do movimento antimanicomial a fim de produzir o giro discursivo que permite sair do discurso do mestre para o discurso do analista.

A reflexão sobre quais contribuições a psicanálise traz para o campo da saúde mental e para o trabalho nos centros de atenção psicossocial está intrinsecamente ligada à emergência do discurso do 
analista no laço social, em que o analista sustenta um lugar de escuta do sujeito em sua diferença. É necessário que o analista se posicione de modo crítico diante do saber institucional e ocupe o lugar de agente que causa no outro uma mudança discursiva, fazendo emergir o discurso analítico, único discurso capaz de dar voz ao sujeito (Lacan, 2003). Esse ato analítico é político na medida em que garante que o sujeito do desejo seja escutado e acolhido e capaz de se responsabilizar pelo seu sofrimento e tratamento. Ainda, esse giro discursivo possibilita a emergência do discurso do analista possibilitando que os técnicos possam vir a ocupar também esse lugar de objeto causa de desejo em transferência.

Esse lugar do 'santo', que se oferece como causa de desejo para o sujeito do inconsciente, recebendo deste o resto do gozo, somente pode ser sustentado no dispositivo analítico, ou seja, situado em uma relação transferencial de escuta flutuante do analista e associação livre que articula os significantes nas aberturas e descontinuidades da fala do sujeito do inconsciente (Lacan, 2003; Ferreira, 2013; Mira, 2005; Rinaldi, 2015).

A ética do desejo coloca o sujeito como centro do trabalho clínico. Assim, o ato terapêutico e político do analista é sustentar o mal-estar do não-saber e estabelecer laços sociais a partir do modo singular como cada um produz seu discurso (Elia, 2010; Tenório, 2002).

Já que o que interessa à psicanálise são as manifestações clínicas manifestadas na fala do sujeito, o espaço coletivo pode permitir a prática analítica desde que exista a transferência e o acolhimento da demanda do sujeito (Lo Bianco, 2015). Compartilha-se a ideia de que é preciso criar serviços que recepcionem o sujeito, através de um suporte teórico e ético (Ferreira, 2013; Rinaldi, 2005; Tenório, 2002), a fim de "propiciar para o indivíduo uma possibilidade de 'fazer sentido" de sua vida e das vicissitudes de sua existência ao longo do tempo, do nascimento à morte" (Rinaldi, 2005, p.134).

\section{Considerações finais}

Ao discutirmos um campo de conhecimento e prática tão complexo e polissêmico como a saúde mental, nos deparamos com perspectivas tão diferentes que ora parecem convergir para a mesma modalidade de cuidado e ora demonstram ter divergências tão profundas que não permitem qualquer tipo de aproximação. Estamos nos referindo à clínica do sujeito em psicanálise e à atenção psicossocial e seu ideal de cidadania.

As palavras sujeito e clínica estão imbuídas de sentidos dúbios, pois não se trata de qualquer clínica e nem de qualquer sujeito, mas do lugar de partida de cada prática discursiva no campo da saúde mental. A clínica psiquiatra tradicional tão intensamente combatida 
pela Reforma Psiquiátrica Brasileira tem sido, muitas vezes, confundida com as demais formas de fazer clínica, incluindo, a clínica psicanalítica.

A clínica do sujeito é um convite para a escuta dos efeitos do inconsciente, para os diferentes modos como cada um se posiciona na linguagem, revelando que há uma estruturação psíquica que pode trazer impasses ao laço social. Nesse sentido, os profissionais podem criar atividades que permitam o enlace do sujeito com a realidade social. Assim, as questões de cidadania podem comparecer enquanto demanda para o sujeito.

Acreditamos que não há uma fórmula para a invenção de novas práticas de cuidado em saúde mental propostas pela Reforma Psiquiátrica. Deste modo, nosso trabalho não traz proposições do tipo "faça isso para alcançar aquilo", uma vez que não esperamos uma massificação do pensamento psicanalítico a ponto de termos práticas iguais quando lidamos com as diferenças das experiências psíquicas. Outros trabalhos psicanalíticos em nossa referência bibliográfica expõem as vivências de analistas nas diversas modalidades de CAPS. Assim, o leitor poderá conhecer as práticas inventivas de cada analista em seu lócus de trabalho, embora, lá também, não se encontre as fórmulas para um trabalho ideal, mas de inspirações para suas próprias criações.

Apostamos na sustentação de um trabalho orientado pela ética do desejo do sujeito do inconsciente pelos analistas que estão inseridos na saúde pública e nos efeitos do saber analítico para o trabalho dos demais profissionais para que possam sustentar um cuidado clínico e psicossocial que considere a demanda e o desejo das pessoas com sofrimento que buscam assistência na rede de atenção psicossocial. Deste modo, mesmo que os psicanalistas não estejam presentes nos serviços de saúde mental enquanto técnicos das equipes de saúde, o analista na função de supervisor clínico-institucional pode demarcar e sustentar esse lugar de escuta do sujeito em sua diferença. Este lugar de supervisor clínico institucional outrora fora ocupado por analistas em nossa realidade de uma rede de atenção integral de saúde mental em um município nordestino $e$, até $o$ presente momento, tem apresentado efeitos no modo de trabalho dos profissionais dos CAPS tipo II e tipo álcool e outras drogas existentes na localidade. Mesmo não ocupando mais tais cargos e com a ausência de psicanalistas nestes serviços públicos de saúde na atualidade, há a presença dos efeitos do trabalho realizado por psicanalistas, a exemplo do que foi percebido na participação das rodas de gestão e dos encontros de apoio matricial durante nossa pesquisa. 


\section{Referências}

Alberti, S. (2000). Apresentação. In S. Alberti \& L. Elia (Orgs.), Clínica e pesquisa em Psicanálise (pp. 7-17). Rio de Janeiro: Rios Ambiciosos.

Amarante, P. (1995). Algumas considerações históricas e outras metodológicas sobre a Reforma Psiquiátrica no Brasil. In P. Amarante (Coord.), Loucos pela vida: a trajetória da reforma psiquiátrica no Brasil (pp. 87-121). Rio de Janeiro: Fiocruz.

Amarante, P. (2003). A (clínica) e a Reforma Psiquiátrica. In P. Amarante (Org.), Archivos de Saúde Mental e Atenção Psicossocial (pp. 45-65). Rio de Janeiro: Nau Editora.

Amarante, P. (2007). Saúde Mental e Atenção Psicossocial. Rio de Janeiro: Fiocruz.

Barros, D. (1994). Cidadania versus periculosidade social: a desinstitucionalização como desconstrução do saber. In $P$. Amarante (Org.), Psiquiatria social e reforma psiquiátrica (pp. 171-193). Rio de Janeiro: Fiocruz; 1994.

Basaglia, F. (1985). As instituições da violência. In F. Basaglia (Org.), A instituição negada: relato de um hospital psiquiátrico (pp. 99133). Rio de Janeiro: Edições Graal.

Basaglia, F. (1979). Saúde e Trabalho. In F. Basaglia, A Psiquiatria Alternativa: contra o pessimismo da razão, o otimismo da prática (pp. 62-73). São Paulo: Ed. Brasil Debates.

Behring, E. R., \& Bochetti, I. (2011). Política Social: fundamentos e história. São Paulo: Cortez.

Birman J. (1992). A cidadania tresloucada: notas introdutórias sobre a cidadania dos doentes mentais. In: B. Bezerra Junior \& P. Amarante (Orgs.), Psiquiatria sem hospício: contribuições ao estudo da reforma psiquiátrica (pp. 71-89). Rio de Janeiro: Relume-Dumará.

Brasil (2011). Portaria no 3.088, de 23 de dezembro de 2011. Institui a Rede de Atenção Psicossocial para pessoas com sofrimento ou transtorno mental e com necessidades decorrentes do uso de crack, álcool e outras drogas, no âmbito do Sistema Único de Saúde (SUS). Recuperado de http://bvsms.saude.gov.br/bvs/saudelegis/gm/2011/prt3088_2 3_12_2011_rep.html

Carvalho, S. R. (2009). Reflexões sobre o tema da cidadania e a produção de subjetividade no SUS. In S. R. Carvalho, M. E. Barros, S. Ferigato (Orgs.), Conexões: Saúde Coletiva e políticas da subjetividade (pp. 23-41). São Paulo: Aderaldo \& Rothschild.

Coutinho Jorge, M. A. (2002). Discurso e liame social: apontamentos sobre a teoria lacaniana dos quatro discursos. In D. Rinaldi \& M. A. Coutinho Jorge (Orgs.), Saber, verdade e gozo: leituras de $O$ 
seminário 17, de Jacques Lacan (pp. 17-32). Rio de Janeiro: Rios Ambiciosos.

Darriba, V. A. (2015). Em que consiste a dita conjunção do capitalismo com a ciência? In R. M. M. Barros \& V. A. Darriba (Orgs.), Psicanálise e Saúde: entre o Estado e o sujeito (pp. 8393). Rio de Janeiro: Companhia das Letras.

Desviat, M. (2015). A Reforma Psiquiátrica. Rio de Janeiro: Fiocruz.

Dunker, C. I. L., \& Neto, F. K. (2015). Psicanálise e Saúde Mental. Porto Alegre: Criação Humana.

Elia, L. (2000). Psicanálise: clínica e pesquisa. In S. Alberti \& L. Elia (Orgs.), Clínica e pesquisa em Psicanálise (pp. 19-36). Rio de Janeiro: Rios Ambiciosos.

Elia, L. (2010). O conceito de sujeito. Rio de Janeiro: Jorge Zahar.

Elia, L. (2015). Política da Psicanálise e Política do Estado: uma exclusão possivelmente fecunda. In R. M. M. Barros \& V. A. Darriba (Orgs.), Psicanálise e Saúde: entre o Estado e o sujeito (pp. 69-82). Rio de Janeiro: Companhia das Letras.

Ferreira, T. (2013). O que a clínica do sujeito nos ensina. In A. M. Lobosque \& C. R. Silva (Orgs), Saúde mental: marcos conceituais e campos de prática (pp. 56-65). Belo Horizonte: CRP 04.

Figueiredo, L. C. (2009). As diversas faces do cuidar: novos ensaios de psicanálise contemporânea. São Paulo: Escuta.

Fleury, S., \& Ouverney, A. M. (2012). Política de Saúde: uma política social. In L. Giovanella, S. Escorel, L. V. C. Lobato, J. C. Noronha, \& A. I. Carvalho (Orgs.), Políticas e Sistemas de Saúde no Brasil (pp. 23-64). Rio de Janeiro: Editora Fiocruz/Centro Brasileiro de Estudos de Saúde.

Foucault, M. (2005). História da loucura: na idade Clássica (19261984). São Paulo: Perspectiva.

Foucault, M. (1979). Microfísica do poder. Rio de Janeiro: Edições Graal.

Freud, S. (2010a). Introdução ao Narcisismo. In P. C. Souza (Coord. \& Trad.), Obras completas: Introdução ao narcisismo, ensaios de metapsicologia e outros textos (Vol. 12, pp. 13-50). São Paulo: Cia da Letras. (Obra original publicada em 1914)

Freud, S. (2010b). Caminhos da terapia psicanalítica. In P. C. Souza (Coord. \& Trad.), Obras completas: História de uma neurose infantil: ("O homem dos lobos"), Além do princípio do prazer e outros textos (Vol. 14, pp. 279-292). São Paulo: Companhia das Letras. (Obra original publicada em 1919)

Freud S. (2016). Três Ensaios sobre a Sexualidade. In P. C. Souza (Coord. \& Trad.), Obras completas: Três Ensaios sobre a Sexualidade, análise fragmentária de uma histeria ("O Caso Dora") e outros textos (Vol. 6, pp. 13-172). Rio de Janeiro: Imago. (Obra original publicada em 1915) 
Furtado, L. A. R., Araújo, A. R. A, \& Santos, S. F. P. (2014). O sujeito autista, a psicanálise e a educação inclusiva. In L. A. R. Furtado \& C. A. L. Vieira (Orgs.), O autismo, o sujeito e a psicanálise: consonâncias (pp. 161-184). Curitiba: CRV.

Lacan, J. (1985). O seminário, livro 20: mais, ainda. Rio de Janeiro: Jorge Zahar. (Obra original publicada em 1972-1973)

Lacan, J. (1988). O seminário, livro 11: os quatro conceitos fundamentais da psicanálise. Rio de Janeiro: Jorge Zahar. (Obra original publicada em 1963-1964)

Lacan, J. (1996) A tópica do imaginário. In J. Lacan, O seminário, livro 1: os escritos técnicos de Freud (pp. 89-139). Rio de Janeiro: Jorge Zahar. (Obra original publicada em 1953-1954)

Lacan, J. (1998). O estádio do espelho como formador da função do eu tal como nos é revelada na experiência psicanalítica. In J. Lacan, Escritos (pp. 96-103). Rio de Janeiro: Jorge Zahar. (Obra original publicada em 1949)

Lacan, J. (2003). Televisão. In J. Lacan, Outros Escritos (pp. 508543). Rio de Janeiro: Jorge Zahar.

Lancetti, A, \& Amarante, P. (2014). Saúde Mental e Saúde Coletiva. In G. W. S. Campos, M. C. S. Minayo, M. Akerman, M. Drumond Jr., \& Y. M. Carvalho (Orgs.), Tratado de Saúde Coletiva (pp. 615-633). São Paulo: Hucitec. Rio de Janeiro: Fiocruz.

Lo Bianco, A. C. (2015). De que sujeito se trata para as intervenções do Estado na área da saúde? In R. M. M. Barros, \& V. A. Darriba (Orgs.), Psicanálise e Saúde: entre o Estado e o sujeito (pp. 151-158). Rio de Janeiro: Cia das Letras.

Marshall, T. H. (1967). Cidadania, classe social e status. Rio de Janeiro: Zahar Editores.

Mira, K. (2005). O psicanalista e as novas instituições de tratamento da psicose. In S. Altoé, \& M. M. Lima (Orgs.), Psicanálise, Clínica e Instituição (pp. 149-160). Rio de Janeiro: Rios Ambiciosos.

Montaño, C. (2007). A natureza do Serviço Social. São Paulo: Cortez.

Resende, H. (1994). Política de Saúde Mental no Brasil: uma visão histórica. In S. A. Tundis, \& N. R. Costa (Orgs.), Cidadania e Loucura: Políticas de Saúde Mental no Brasil (pp. 15-73). Petrópolis: Vozes/ABRASCO.

Rinaldi, D. (2002). O desejo do psicanalista no campo da saúde mental: problemas e impasses da inserção da psicanálise em um hospital universitário. In D. Rinaldi \& M. A. Coutinho Jorge (Orgs.), Saber, verdade e gozo: leituras de O seminário 17, de Jacques Lacan (pp. 53-69). Rio de Janeiro: Rios Ambiciosos.

Rinaldi, D. (2005). Clínica e política: a direção do tratamento psicanalítico no campo da saúde mental. In S. Altoé \& M. M. Lima (Orgs.), Psicanálise, Clínica e Instituição (pp. 87-106). Rio de Janeiro: Rios Ambiciosos. 
Rinaldi, D. (2006). Entre o sujeito e o cidadão: psicanálise ou psicoterapia no campo da saúde mental. In S. Alberti \& A. C. Figueiredo (Orgs.), Psicanálise e Saúde Mental: uma aposta (pp. 141-148). Rio de Janeiro: Cia de Freud.

Tenório, F. (2002). A reforma psiquiátrica brasileira, da década de 1980 aos dias atuais: história e conceitos. Revista História, Ciências, Saúde - Manguinhos, 9(1), 25-59. doi:10.1590/S0104-59702002000100003

\section{Endereço para correspondência \\ Joyce Hilario Maranhão}

Universidade Estadual do Ceará

Av. Dr. Silas Munguba, número 1700, bloco P, Campus do Itaperi, CEP 60741-000, Fortaleza - CE, Brasil

Endereço eletrônico: joyce_hilario@hotmail.com

\section{Camilla Lopes Araújo Vieira}

Universidade Federal do Ceará

Av. Comandante Maurocélio Rocha Pontes, 100, Campus Sobral, CEP 60042-280, Sobral - CE, Brasil

Endereço eletrônico: tgd.camilla@gmail.com

Recebido em: 04/11/2018

Reformulado em: 21/06/2019

Aceito em: 17/09/2019

\section{Notas}

* Mestra em Saúde da Família.

** Doutora em Saúde Coletiva.

Agradecimento: As autoras agradecem ao Programa de Pós-Graduação em Saúde da Família da Universidade Federal do Ceará- campus Sobral - ao qual estavam vinculadas na época da pesquisa - e à Coordenação de Aperfeiçoamento de Pessoal de Nível Superior-CAPES pela disponibilização de bolsa a uma das pesquisadoras durante seu mestrado acadêmico.

Este artigo de revista Estudos e Pesquisas em Psicologia é licenciado sob uma Licença Creative Commons Atribuição-Não Comercial 3.0 Não Adaptada. 